\title{
LA ESCALA MÉTRICA EN LA POLIMETRÍA ROMÁNTICA
}

\author{
ISABEL PARAÍSO
}

\section{Polimetría y heteroestrofía en la métrica romántica}

$\mathrm{E}$

Romanticismo tiene, en la historia de nuestro verso hispánico, la gran misión de transformar el lenguaje poético en un instrumento altamente sensible, muy dúctil y maleable, que por una parte prolongará un conjunto de formas (heredadas de los períodos anteriores y modificadas a menudo ahora); y, por otra parte, conducirá hasta las puertas mismas del verso libre en las décadas finales del siglo XIX -sobre todo en sus poetas más tardíos: Bécquer (1836-1870), Rosalía (1837-1885), Rafael Núñez (Colombia, 1828-1894)-.

Los tres rasgos distintivos de esta métrica romántica son, a nuestro entender: tradicionalidad, innovación y espíritu de libertad. Dentro de sus numerosas manifestaciones, vamos a centrarnos hoy en un tipo de versificación muy llamativo y característico. Es el que mezcla diversos esquemas en una misma composición poética. Nuestros estudiosos lo denominan polimetría. Como su nombre indica, la polimetría consiste en la mezcla de muchos metros (o al menos varios) en un mismo poema.

El concepto de "polimetría", sin embargo, a menudo va más allá de su nombre, puesto que engloba no sólo la mezcla de varios metros, sino también la mezcla de varios tipos poemáticos. Una composición polimétrica (por ejemplo, una "ensaladilla" del Siglo de Oro), puede contener unos trozos en 
romance o romancillo, otros en copla castellana o en canción trovadoresca, y otros en redondilla.

La polimetría, por tanto, es un paso adelante respecto a la "heterometría”, que combina en una forma poemática dos metros, raramente tres, y casi siempre de manera regulada: las coplas medievales de pie quebrado, o los cuartetos-lira y las silvas en el Renacimiento, nos suministran ejemplos de heterometría.

La polimetría supone una mezcla mayor que la heterometría: reúne diversos metros y tipos poemáticos, y su aparición queda al arbitrio del poeta. El poema polimétrico, a menudo extenso, parece compuesto por trozos de varios.

Los estudiosos franceses hablan en este caso de "hétérostrophie”. Entienden por ello la mezcla, en un solo poema, de varios esquemas estróficos. En nuestro libro La métrica española en su contexto románico hemos utilizado ambas palabras (polimetría y heteroestrofía) como cuasi-sinónimas, puesto que habitualmente los poemas polimétricos son también, al mismo tiempo, heteroestróficos. Hacíamos en este libro la salvedad de que, a menudo, para la literatura española la denominación de "heteroestrofía” no es exacta, puesto que los poemas polimétricos suelen contener partes en romance o romancillo, que es un tipo de poemático no estrófico. Pero, en conjunto, éramos partidarios de introducir el concepto de "heteroestrofía" junto al de “polimetría”. Y denominábamos "poema mixto” a aquél que contiene más de un tipo poemático en su interior, englobando bajo esta denominación tanto a la polimetría como a la heteroestrofía.

La métrica romántica es la más idónea para examinar estos conceptos, ya que la polímetría (y/o heteroestrofía) es una de sus manifestaciones más destacadas. Tanto, que un poeta como Zorrilla en sus escritos primeros sólo utiliza tipos poemáticos polimétricos y heteroestróficos. Por ejemplo, el primer poema de sus Obras Completas, el que le dio a conocer en el entierro de Larra ("A la memoria desgraciada del joven literato D. Mariano José de Larra”, 1837) contiene versos endecasílabos seguidos de partes intercaladas en octosílabos; y en cuanto a 
los tipos estróficos incluye quintetos, octavas agudas, redondillas y quintillas. Poema mixto, pues, con polimetría y con heteroestrofía.

Creemos que el Romanticismo, más acusadamente aún que el Neoclasicismo, busca la musicalidad del verso, y en esta búsqueda a menudo vuelve los ojos hacia el teatro y sus formas cantadas. ${ }^{1}$ Por ejemplo, la llamada octavilla romántica (y su expansión al arte mayor, en la octava romántica o bermudina), ${ }^{2}$ se remonta a la quartina doppia de las odi e canzonette del Settecento italiano. ${ }^{3}$

Nos parece, pues, que esta predilección romántica por el poema mixto procede, fundamentalmente, de la lírica cantada, ${ }^{4} \mathrm{y}$ de modo secundario, del amor a la poesía tradicional española del Siglo de Oro, en cuyo teatro y lírica también se encuentra la polimetría abundantemente representada.

La poesía romántica, que tanto utiliza el poema mixto, nos enseña que debemos distinguir entre heteroestrofía y polimetría, aunque a menudo coincidan. Un ejemplo de coincidencia lo tenemos en "El mendigo" de Espronceda. Por una parte vemos polimetría (versos de 11 sílabas en ciertas partes, versos de 8 y de 4 en otras,y mezcla de 11 y de 8 en otras); y además tenemos heteroestrofía, pues usa coplas asonantes endecasílabas,

${ }^{1}$ «La libertá metrica é una caratteristica anche della poesía scenica, tendente alla polimetria», señala Pietro Beltrami (1994: 125) para la poesía italiana.

${ }^{2}$ Cfr. I. Paraíso (2000: 272-274). La octavilla aguda -también llamada octavilla romántica, por el amplísimo uso que el Romanticismo hace de ella- es italiana de origen: surge en los cantabili del siglo xvIII, y es divulgada por los melodramas de Metastasio (1698-1782). En España está documentada en Gerardo Lobo (16791750). A su vez, la octava romántica o aguda fue popularizada por Salvador Bermúdez de Castro entre 1835 y 1840. Su majestuosidad la hace apta para la narrativa y la lírica.

${ }^{3}$ Cfr. Francesco Bausi y Mario Martelli (1993: 205-208). Concretamente, sobre el esquema más difundido en España (øaaé:øbbé), señalan que en la literatura italiana es fortunatissimo, y citan poemas de Frugoni, Meli, Fantoni y Parini.

${ }^{4}$ Tomás Navarro Tomás (1991: § 283) señala que la lírica cantada, que se había mantenido al margen de la Métrica durante el Neoclasicismo, es una de las influencias de la métrica romántica. «La diversidad de metros y estrofas se había aplicado también al poema narrativo. La poesía romántica venía a desarrollar esta práctica, aplicándola principalmente a su nuevo género de cuentos o leyendas en verso». 
cuartetas heterométricas, sextillas heterométricas agudas, octavillas, sextillas y decimillas románticas.

\section{La escala métrica}

El poema mixto más llamativo del Romanticismo es, sin duda, la escala métrica. Frente a la inmensa mayoría de poemas mixtos que poseen polimetría (o heteroestrofía) libre (es decir, combinan metros o tipos poemáticos a gusto del poeta, sin orden previo), la escala métrica es un caso claro de polimetría regulada. Entendemos por “polimetría regulada” la mezcla de versos que viene condicionada por un patrón externo, al cual el poeta se ajusta.

La escala métrica es un poema mixto, extenso, que va utilizando sucesivos esquemas versales en orden gradualmente creciente de sílabas (de menor a mayor), o bien en orden decreciente (de mayor a menor). Incluso a menudo se encuentra en orden doble: ascendente-descendente (en figura de rombo), o descendente-ascendente (en figura de dos triángulos unidos por el vértice).

Supone, para el poeta que la cultiva, una proeza técnica. El reto consiste en ajustar ese lenguaje de molde prefijado a un contenido específico, a unas situaciones temáticas cambiantes, que justifiquen la gran diversidad formal. El poeta que escribe escalas métricas exhibe su dominio del lenguaje poético.

El poema “Les Djinns” de Victor Hugo (1828) marcó una forma métrica para las escalas, y también una temática: la manifestación súbita de lo pavoroso o sobrehumano. Esta "fantasía” oriental de Hugo describe el ataque nocturno de un enjambre de pequeños seres maléficos. La nota de horror, tan romántica, cuaja y se prolonga, con variantes, en las escalas hispánicas. A lo largo del Romanticismo hispánico, la escala métrica va a servir para transcribir sufrimiento nocturno, horribles pesadillas, o espectrales situaciones sobrenaturales.

El poema de Hugo es imitado por el venezolano Andrés Bello en 1843. Y en la literatura española, entre 1836 y 1889, 
encontramos un conjunto de escalas: dos en Espronceda (ambas en El estudiante de Salamanca, escrito entre 1836 y 39); una en Gertrudis Gómez de Avellaneda ("La noche de insomnio y el alba”, 1841); y cuatro en Zorrilla. Tres de las cuatro de Zorrilla fueron escritas en su plenitud poética: "La azucena silvestre”, 1845; "Un testigo de bronce”, 1845; y "Leyenda de Al-Hamar”, 1852. Y la cuarta fue escrita en su vejez: "Recuerdo del tiempo viejo” (1889). Tiene la peculiaridad de ser triple $\mathrm{y}$ descendentes en sus tres partes.

De una manera epigonal, hallaremos aún otra en el jovencísimo Rubén Darío (“Tú y yo”, c. 1880-86). La escala de Darío, tan tardía, cambia de temática y recoge las ensoñaciones amorosas del poeta.

En cuanto a la adaptación al español de la forma métrica de Hugo, el único poeta que sigue estrictamente sus medidas -ha señalado T. Navarro Tomás- ${ }^{5}$ es Andrés Bello. Porque «las escalas de Espronceda y Zorrilla y en especial de la Avellaneda ensancharon considerablemente el marco del modelo francés».

Podemos fechar, pues, la vida literaria de la escala métrica entre 1828 y 1889: sesenta y un años. Con un introductor genial, Víctor Hugo, entonces en su plenitud poética, y con dos poetas igualmente geniales que la cierran: Zorrilla en sus postrimerías poéticas, y Rubén Darío en sus años de aprendizaje adolescente.

\section{1. Víctor Hugo, el creador (1828)}

La invención de la escala métrica se debe a Victor Hugo (1802-1885), con su poema “Les Djinns". Fue compuesto el 25 de agosto de 1828, y apareció incluido en Les Orientales, 1829.

En la "Préface" de este libro, Hugo se refiere a "Les Djinns" como «fantaisie», «caprice», y también «de la poésie pour les yeux». Después de las visiones apocalípticas, dantescas y miltonianas, que cultiva entre 1821 y 1823, después de las Ballades (1825) donde evoca una Edad Media fantástica, se inclina Hugo por el ensueño oriental. En 1824 considera a la Edad Media y a Oriente como los dos “mares de poesía”, y en 1825 escribe

${ }^{5}$ T.Navarro Tomás (1991: § 360). 
su primera “Oriental”. ${ }^{6}$ La investigación rítmica del poeta, que había empezado en Ballades, se intensifica en Les Orientales y culmina en "Les Djinns". El poema fue encomiado por SainteBeuve y gozó de fama mundial.

Temáticamente, describe un ambiente nocturno, fantástico, en medio del cual aparece de pronto el enjambre de los “djinns” que se abate sobre la ciudad y ataca ferozmente la casa del poeta. Implora éste al "Profeta”(Mahoma), le promete ir a La Meca ( «prosterner mon front chauve / devant tes sacrés encensoirs!»), y los “djinns” se alejan hasta desaparecer en la noche. ${ }^{7}$

Métricamente, encontramos versos que, según el cómputo francés -que toma en consideración desde la primera sílaba hasta la última acentuada del verso, desentendiéndose del resto-, tenemos metros con estas sílabas: $2,3,4,5,6,7,8,10,8,7,6$, $5,4,3$, y 2. (Sólo faltan los versos de 9 sílabas, pues, entre las 2 y las 10). ${ }^{8}$

En cuanto a la estrofa empleada, es siempre la misma: una octavilla u octava romántica (el «huitain romantique»), ${ }^{9}$ cuyo esquema es: AÉAÉ:BBBÉ. Podemos hablar, por lo tanto, de polímetría, pero no de heteroestrofía.

Hugo consagra exactamente una estrofa a cada uno de los metros citados, reservando los más breves para la descripción del apacible ambiente nocturno, y los más largos para el ataque furioso de los “djinns”. La octava culminante, aquella en que

${ }^{6}$ Lord Byron había muerto en 1824, en la batalla de Missolonghi, luchando por la independencia de los griegos. La simpatía en toda Francia por la causa griega repercute sobre Les Orientales, dándoles actualidad.

Hugo toma algunos epígrafes árabes y persas en Odes et Ballades, y en junio de 1820 reseña el libro de Thomas Moore Lalla-Roukh, o La Princesa Mongola.

${ }^{7}$ Pierre Albouy, en sus notas a este poema en las E Euvres poétiques de Hugo, señala que estos "djinns" tienen poco que ver con los del Corán o Las mil y una noches (aunque puedan atacar al viajero o colarse en las casas mal cerradas). Pero por el ruido de cadenas y su espectralidad se parecen más a los de la mitología medieval (ronda del Sabbat, vampiros, etc.).

${ }^{8}$ Véase el análisis que de “Les Djinns” realiza Maurice Grammont (1967: 182-184).

${ }^{9}$ Michéle Aquien (1992: 106) menciona el «huitain romantique» y señala su rima: ababcccb. Nosotros indicamos la rima aguda mediante vocal, como es costumbre entre los autores españoles. 
el enjambre de "djinns" se abate sobre la morada del poeta, es precisamente la de metros más largos. ${ }^{10}$

\section{2. La imitación de Bello (1843)}

Dentro de su amplísima labor educativa, en la cual la poesía propia ocupa un puesto menor, el venezolano Andrés Bello (Caracas, 1781 - Chile, 1865), autor de las "Silvas americanas" (1823 y 1827), también cultiva la escala métrica. Se inspira en ella para su poema "Los duendes. Imitación de Víctor Hugo" (1843).

Lo primero que observamos es su extensión muy superior. Frente a los 120 versos de Hugo, Bello escribe nada menos que 311. En segundo lugar, frente a la uniformidad estrófica de las octavas de Hugo, la irregularidad de las partes (numeradas) de Bello, que contienen diversos conjuntos de versos entre los 10 y los 34. Bello, por tanto, mantiene la polimetría de Hugo, pero la acompaña con heteroestrofía.

En lo que el poeta venezolano sigue "casi" fielmente al francés es en la estructura de la polimetría: en el rigor ascendentedescendente de la escala (forma de rombo), y también en el número de sílabas de cada metro.

Recordemos que Hugo va desde el bisílabo hasta el decasílabo francés. Según el cómputo español, que tiene en cuenta la sílaba átona final o computa un tiempo más en las rimas agudas, esos versos se transformarían en estas medidas: 3, 4, 5, 6, 7, 8, 9, 11, 9, 8, 7, 6, 5, 4 y 3 sílabas. Éstos son exactamente los metros que Bello emplea; pero además "repara” la omisión de Hugo, el decasílabo, introduciendo en las dos ramas -ascendente y descendente- conjuntos de versos decasílabos dactílicos.

${ }^{10}$ Oigamos cómo suena la octavilla (u octava) de Hugo en dos de sus estrofas más destacadas: la primera y la número ocho -la más extensa en sílabas: décasyllabes-. (Transcribimos los versos seguidos, separados por trazos oblicuos, con el fin de ganar espacio):

«Murs, ville, / Et port, / Asile / De mort, / Mer grise / Où brise / La brise, / Tout dort.» [...]// «Cris de l'enfer! voix qui hurl'e et qui pleure! / L'horrible essaim, poussé par l'aquilon, / Sans doute, ô ciel! s'abat sur ma demeure. / Le mur fléchit sous le noir bataillon. / La maison crie et chancelle penchée, / Et l'on dirait que, du sol arrachée, / le vent la roule avec leur tourbillon!». 
Aquí se terminan las semejanzas métricas entre Bello y Hugo, ya que los tipos poemáticos que integran ambas escalas son totalmente diferentes. Hugo opta por la regularidad de las octavillas u octavas (huitain romantique); Bello, por el romancillo para los conjuntos de versos más breves (entre las 3 y las 6 sílabas), y por la serie con rima de libre distribución, para los conjuntos de versos más extensos (entre las 7 sílabas y las 11, y desde éstas nuevamente a las 7).

En algunas de estas series, la rima adopta disposiciones juguetonas ocasionales: tendente al pareado $(\mathrm{V}, \mathrm{XI}),{ }^{11}$ tendente al monorrimo (VII), ${ }^{12}$ o reuniendo rimas próximas (X: -ina / -ana/ -ena: en onomatopeya del tañido de la campana de la iglesia, que finalmente ahuyenta a los duendes). ${ }^{13}$

Temáticamente también hay divergencias menores, fruto de la "adaptación" que Bello realiza de la "oriental" a su ambiente vital americano: La invocación al Profeta se transforma en invocaciones a la Virgen del Carmelo (parte V) y a San Antón (VII); la irrealidad semifantasmal de la noche en Hugo se convierte en una serena ambientación del atardecer (parte I) y de la noche (XVII). Incluso Bello, tras comprobar que su huerta no ha sufrido daño (XIII), se apiada de los duendes (XIV, XV, XVI).

En todo caso, la escala de Bello es la que, desde el punto de vista de los metros empleados, en la temática, e incluso en el tratamiento juguetón del tema, sigue más fielmente a su predecesor, Victor Hugo. De ahí el subtítulo de “imitación”.

${ }^{11}$ Por ejemplo, en el grupo V: «A casa me recojo; / echemos el cerrojo. / ¡Qué triste y amarilla / arde mi lamparilla!» (etc.) O bien en el XI: «iPartieron! La sonante nota/ a la hueste infernal derrota. / Uno a otro apresura, excita, / estrecha, empuja, precipita» (etc.).

12 «San Antón, no soy tu devoto, / si no le pones luego coto / a este diabólico alboroto. / ¡Motín semeja, o terremoto, / o hinchado torrente que ha roto» (etc.).

${ }^{13}$ « $\mathrm{A}$ h! Por fin en la iglesia vecina / a sonar comenzó la campana... / Al furor, a la loca jarana, / turbación sucedió repentina. / El tañido de aquella campana / a la hueste infernal amohína, / sobrecoge, atolondra, amilana. / Como en pecho abrumado de pena / una luz de esperanza divina; / como el sol en la densa neblina, / de los montes rizada melena» (etc.). 


\section{3. La escala en Espronceda (1836-39)}

Cronológicamente, el primer poeta que en España cultiva la escala métrica es el extremeño José de Espronceda (18081842).

Sus dos escalas aparecen en El estudiante de Salamanca (subtitulado “cuento" y escrito entre 1836 y 1839). En la primera parte vemos una escala ascendente bastante breve (51 versos), que consta de: trisílabos (4 versos), tetrasílabos (11), octosílabos (12) y dodecasílabos (24). Los tipos poemáticos que aparecen son, respectivamente: series con rima de libre distribución, romances y serventesios. Esta primera escala de Espronceda presenta, pues, tanto polimetría como heteroestrofía.

En la cuarta parte de la misma obra, El estudiante de Salamanca, encontramos otra escala mucho más famosa, que da forma precisamente a la escena culminante del poema: la boda de don Félix de Montemar con la Muerte. Esta segunda escala es mucho más extensa (296 versos).

Es ascendente-descendente (en forma de rombo, como la de Hugo). Comienza con versos de 2 y 3 sílabas $^{14}$ (6 versos), continúa con tetrasílabos (9), pentasílabos (13), hexasílabos (27), heptasílabos (8), octosílabos (22), eneasílabos dactílicos (16), decasílabos dactílicos (16), endecasílabos (20) y dodecasílabos compuestos (32). A partir de aquí comienza el descenso con endecasílabos de nuevo (16), decasílabos dactílícos (16), eneasílabos dactílicos (16), octosílabos (16), heptasílabos (16), hexasílabos (16), pentasílabos (12), tetrasílabos (8), trisílabos (8) y bisílabos ${ }^{15}(3)$.

${ }^{14}$ Por abreviar, decimos que el primer conjunto de la escala, una sextilla, consta de versos de 2 y 3 sílabas. Son los siguientes: «Fúnebre / Llanto / De amor, / Oyese / En tanto / En son». Computando estrictamente, encontraríamos estas medidas: 2-2-3-2-3-3 sílabas. Sin embargo, creemos que Espronceda, en estos versos como en otros muchos lugares (comienzo de El diablo mundo, por ejemplo) se deja llevar por la música de las palabras, y comienza a enlazar unos versos con otros, en sinafías y compensaciones que desdibujan el cómputo estricto silábico. Personalmente, leemos: «Fúnebre / Llanto de a- / mor, / Oyese en / tanto en / son»: 3-3-1: 3-3-1 sílabas gramaticales (no métricas; éstas serían: 3-3-2: 3-3-2).

${ }^{15}$ Es sintomático que Espronceda termine su escala con palabra monosílaba («Leve, / Breve / Son»). Muestra la atención del poeta no sólo a los valores métricos, sino también a los valores gramaticales y semánticos. 
Espronceda amplía, pues, los metros usados por Hugo. Por debajo, incluyendo los bisílabos (los bisyllabes de Hugo en español son interpretados como trisílabos); y por encima, incluyendo los metros de 12 sílabas.

En cuanto a los tipos poemáticos que aparecen en esta escala, encontramos fundamentalmente serventesios junto a octavas y octavillas agudas, romance, sextilla, y series de versos breves con rima de libre distribución. Al igual que Bello (a quien antecede cronológicamente), Espronceda usa no sólo polimetría sino también heteroestrofía.

Esta escala de Espronceda constituye una de las piezas más famosas de la literatura española. Citada hasta nuestros días en libros de texto y en libros de métrica, es un referente para la literatura nacional. ${ }^{16}$

\section{4. La escala en Avellaneda (1841)}

La cubana Gertrudis Gómez de Avellaneda (1814-1873) compone en "La noche de insomnio y el alba. Fantasía" (Poesías, 1841) la escala más sistemática y con mayor abundancia de metros que existe en lengua española: Contiene versos de todas las medidas, entre las 2 y las 16 sílabas. Espronceda -acabamos de verlo- había ampliado la escala de Hugo con metros entre las 2 y las 12 sílabas. Avellaneda irá mucho más lejos, al incluir los metros de 13, 14, 15 y 16 sílabas.

${ }^{16}$ Veamos algunos versos de este inmortal poema: algunos octosílabos y algunos endecasílabos de la rama ascendente, y luego, de la descendente, algunos pentasílabos además de los trisílabos y bisílabos finales.

«Y algazara y gritería, / Crujir de afilados huesos, / Rechinamiento de dientes / Y retemblar los cimientos, / Y en pavoroso estallido / Las losas del pavimento / Separando sus junturas / Irse poco a poco abriendo, [...] // ¡Es su esposo! los ecos retumbaron, / ¡La esposa al fin que su consorte halló! / Los espectros con júbilo gritaron: / iEs el esposo de su eterno amor! // Y ella entonces gritó: ¡Mi esposo! Y era / (¡Desengaño fatal! ¡triste verdad!) / Una sórdida, horrible calavera, / La blanca dama del gallardo andar!... [...]// Y siente luego / Su pecho ahogado, / Y desmayado, / Turbios sus ojos, / Sus graves párpados, / Flojos caer [...] // Tal, dulce / Suspira / La lira / Que hirió / En blando / Concento / Del viento / La voz. // Leve, / Breve / Son». 
Es una escala sólo ascendente (en forma de triángulo), igual que la primera de Espronceda. En ella narra sus angustiosas sensaciones en las tinieblas del desvelo, y el progresivo renacer de su espíritu con la llegada del alba, primero tenue y luego esplendorosa al salir el sol. He aquí el textos: ${ }^{17}$

Noche

Triste

Viste

Ya,

Aire

Cielo, Suelo,

Mar.

Brindándole

Al mundo

Profundo

Solaz,

Derraman

Los sueños

Beleños

De paz;

Y se gozan

En letargo

Tras el largo

Padecer,

Los heridos

Corazones

Con visiones

De placer.
(2)

(3)

(4)

${ }^{17}$ Para mejor visualización de sus estrofas, las separamos mediante blancos y las transcribimos como octavillas u octavas (en las Poesías de Avellaneda aparecen sangradas de cuatro en cuatro versos, en forma tipográfica de cuarteta o serventesio doble, y además con los versos todos seguidos, sin espaciados entre las estrofas cuyos metros van cambiando). Añadimos también, en el margen derecho, el número de sílabas de cada conjunto. 
Mas siempre velan

Mis tristes ojos;

Ciñen abrojos

Mi mustia sien;

Sin que las treguas

Del pensamiento

A este tormento

Descanso den.

El mudo reposo

Fatiga mi mente;

(6)

La atmósfera ardiente

Me abrasa doquier;

$\mathrm{Y}$ en torno circulan

Con rápido giro

Fantasmas que miro

Brotar y crecer.

¡Dadme aire! Necesito

De espacio inmensurable,

Do del insomnio al grito

Se alce el silencio y hable!

Lanzadme presto fuera

De angostos aposentos...

¡Quiero medir la esfera!

¡Quiero aspirar los vientos!

Por fin dejé el tenebroso

Recinto de mis paredes...

Por fin, ¡oh espíritu!, puedes

por el espacio volar...

Mas, ¡ay!, que la noche oscura,

Cual un sarcófago inmenso,

Envuelve con manto denso

Calles, campos, cielo, mar.

$\mathrm{Ni}$ un eco se escucha, ni un ave

Respira, turbando la calma;

Silencio tan hondo, tan grave, Suspende el aliento del alma. 
El mundo de nuevo sumido

Parece en la nada medrosa;

Parece que el tiempo rendido

Plegando sus alas reposa.

Mas ¡qué siento!... ¡Balsámico ambiente

Se derrama de pronto!... El capuz

De la noche rasgando, en Oriente

Se abre paso triunfante la luz.

¡Es el alba! Se alejan las sombras,

Y con nubes de azul y arrebol

Se matizan etéreas alfombras,

Donde el trono se asiente del sol.

Ya rompe los vapores matutinos

La parda cresta del vecino monte;

Ya ensaya el ave sus melifluos trinos;

Ya se despeja inmenso el horizonte.

Tras luenga noche de vigilia ardiente

Es más bella la luz, más pura el aura...

¡Cómo este libre y perfumado ambiente

Ensancha el pecho, el corazón restaura!

Cual virgen que el beso de amor lisonjero

Recibe agitada con dulce rubor,

Del rey de los astros al rayo primero

Natura palpita bañada de albor.

Y así, cual guerrero que oyó enardecido

De bélica trompa la mágica voz,

Él lanza impetuoso, de fuego vestido,

Al campo del éter su carro veloz.

¡Yo palpito, tu gloria mirando sublime,

Noble autor de los vivos y varios colores!

¡Te saludo si puro matizas las flores!

¡Te saludo si esmaltas fulgente la mar!

En incendio la esfera zafírea que surcas

Ya convierte tu lumbre radiante y fecunda, Y aún la pena que el alma destroza profunda Se suspende mirando tu marcha triunfal. 
¡Ay! de la ardiente zona do tienes almo asiento, Tus rayos a mi cuna lanzaste abrasador...

¡Por eso en ígneas alas remonto el pensamiento, $\mathrm{Y}$ arde mi pecho en llamas de inextinguible amor! Mas quiero que tu lumbre mis ansias ilumine, Mis lágrimas reflejen destellos de tu luz, Y sólo cuando yerta la muerte se avecine La noche tienda triste su fúnebre capuz.

¡Qué horrible me fuera, brillando tu fuego fecundo, Cerrar estos ojos, que nunca se cansan de verte; En tanto que ardiente brotase la vida en el mundo, Cuajada sintiendo la sangre por hielo de muerte! ¡Horrible me fuera que al dulce murmurio del aura, Unido mi ronco gemido postrero sonase; Que el plácido soplo que al suelo cansado restaura, El último aliento del pecho doliente apagase!

¡Guarde, guarde la noche callada sus sombras de duelo, Hasta el triste momento del duelo que nunca termina; Y aunque hiera mis ojos, cansados por largo desvelo, Dale, ¡oh sol! a mi frente, ya mustia, tu llama divina! Y encendida mi mente, inspirada con férvido acento, -Al compás de la lira sonora- tus dignos loores

Lanzará, fatigando las alas del rápido viento, A do quiera que lleguen triunfantes tus sacros fulgores!

La escala de Avellaneda es la más perfecta de la literatura hispánica, ya que -igual que Víctor Hugo- va dedicando la misma extensión a cada uno de los metros: 8 versos, una octavilla u octava (según sean los metros de arte menor o mayor). No obstante -a diferencia de Hugo--, el tipo de octavilla u octava no es siempre exactamente el mismo: Tenemos dos tipos, que en el poema funcionan como variantes: la octavilla u octava aguda, y la que podríamos llamar octavilla de doble cuarteta ${ }^{18}$ u octava de doble serventesio (ampliación al arte mayor de aquélla). Los dos

${ }^{18}$ Recordemos la quartina doppia italiana del Settecento. 
núcleos de este segundo tipo no están unidos por la rima, a diferencia de los del primer tipo.

La variedad aguda predomina al principio del poema, en el arte menor, y la de doble serventesio al final. La aguda aparece en 7 ocasiones: En los conjuntos de 2 sílabas, de 3, de 4, de 5, de 6, de 8 , y de 13 sílabas. A su vez, en 8 ocasiones encontramos octavilla de doble cuarteta u octava de doble serventesio: En los conjuntos de 7 sílabas, de 9 , de 10 , de 11, de 14, de 15 y de 16 sílabas. Predominan, pues, en el arte mayor.

El hecho de que formalmente sean dos tipos distintos, no quita para que el lector del poema los perciba como una sola forma: la octava, los 8 versos. El esquema estrófico impone su periodicidad por encima de las diferencias que establece la rima.

(Sobre esta curiosa octava compuesta por dos serventesios, digamos que ya Espronceda la había utilizado en "El canto del cosaco”).

Interpretando, pues, ambos tipos de octavillas u octavas como variantes, podríamos hablar en Avellaneda, igual que en Hugo, de polimetría, pero no de heteroestrofía.

Obsérvese, por otra parte, la fuerte tendencia al monorritmo en la mayor parte de las octavas. La octavilla bisílaba contiene necesariamente un esquema trocaico; al igual que la trisílaba, con la primera sílaba en anacrusis, y la tetrasílaba, con las dos primeras sílabas en anacrusis. A partir de la octavilla de 6 sílabas, el monorritmo se focaliza sobre la cláusula dactílica, y en ritmo dactílico uniforme encontramos también la octava de 9 sílabas, la de 10 , la de 12 , la de 13 , la de 15 , y finalmente la de 16 sílabas. ${ }^{19}$ Las demás son polirrítmicas: mezclan varios esquemas acentuales.

El esquema ternario, dactílico, además de uniformar el ritmo de todas esas octavas, tiene otra importante consecuencia: permite que -salvando el alejandrino-, los versos largos pares, que

${ }^{19}$ Por ejemplo: «El mudo reposo» (v-vv-v); «Ni un eco se escucha, ni un ave» (v-vv-

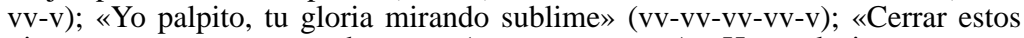
ojos, que nunca se cansan de verte» (v-vv-vv-vv-vv-v); «Hasta el triste momento del sueño que nunca termina» (vv-vv-vv-vv-vv-v). 
tienen la posibilidad de ser simples o compuestos, sean todos simples: decasílabo simple dactílico, dodecasílabo simple dactílico, ${ }^{20}$ e incluso -mucho más original-, el hexadecasílabo simple dactílico.

Digamos, para finalizar nuestro examen, que la escala de Avellaneda es muy importante en la métrica hispánica, no sólo por su sistematicidad en los metros usados y en el ritmo, sino sobre todo porque en ella aparecen por primera vez algunos metros: el tridecasítabo dactílico simple, el pentadecasílabo dactílico simple, y el hexadecasílabo dactílico simple.

El ritmo dactílico sirve de base a la poetisa cubano-española para sus innovaciones. Espronceda en "El verdugo" había usado ya el decasílabo dactílico simple y el dodecasílabo dactílico simple; pero ahora Avellaneda extiende ese mismo ritmo dactílico simple hasta unos límites -las 13, las 15, las 16 sílabas-inéditos en nuestra lengua. Los futuros modernistas prolongarán su audacia.

\section{5. La escala en Zorrilla (1845-52; 1889)}

El vallisoletano José Zorrilla (1817-1893) usará la escala métrica de manera más persistente que sus predecesores: 4 veces. Aparecen estas escalas en "La azucena silvestre" (1845), "Un testigo de bronce" (1845); y "Leyenda de Al-Hamar" (1852). A ellas se puede añadir una escala triple, en las partes II, III y IV de "Recuerdo del tiempo viejo" (1889).

Además de cultivar la escala más que los anteriores poetas, hay que señalar que en las tres primeras ocasiones Zorrilla presentará la originalidad de invertir la figura geométríca de Víctor Hugo, continuada por Bello y por Espronceda en su segunda escala: el rombo se transforma en doble triángulo unido por el vértice. Sus escalas, en lugar de ser ascendente-descendentes, lo

$\overline{{ }^{20}}$ La única duda que podría cabernos en este considerar dactílicos simples los versos largos pares, estribarla en el dodecasílabo, que puede ser interpretado como simple, o bien como compuesto (verso de arte mayor). Nos inclinamos por verlo como simple («Cual virgen que el beso de amor lisonjero», v-vv-vv-vv-v) por asimilación a los demás conjuntos simples. 
serán descendente-ascendentes, de más a menos y luego de menos a más. No conocemos precedente para esta forma de escala, por lo que nos inclinamos a pensar que pueda ser innovación del poeta vallisoletano.

Por el contrario, en la escala triple tardía de "Recuerdo del tiempo viejo”, la figura es descendente, de más a menos. Inversa, pues, al triángulo creciente de Avellaneda.

En tercer lugar, hay que destacar que dos de estas escalas (“Un testigo de bronce” y “Leyenda de Al-Hamar”) tienen la peculiaridad de que ambas ramas, la descendente y la ascendente, están separadas entre sí por un amplio conjunto de versos. Podrían ser interpretadas, pues, como dos escalas en cada caso. No obstante, preferimos considerarlas como entidades únicas con versos incrustados en el vértice de ambos triángulos.

Veámoslas ahora con mayor detención.

En el capítulo cuarto de "La azucena silvestre" Zorrilla nos avisa de su escala mediante este subtítulo: "Donde verá el lector un capricho que tuvo el autor al escribir la presente leyenda”. El "capricho" consiste en una escala descendente-ascendente que incluye 328 versos. Éstos se reparten entre los metros siguientes: de 14 sílabas (8); de 12 (dodecasílabos compuestos, 4); de 11 (4); de 10 (simples dactílicos, 4); de 8 (4); de 7 (12); de 6 (20); de 4 (167); ${ }^{21}$ de 3 (31); de 2 (6); de 3 (8); de 4 (8); de 5 (8); de 6 (8); de 7 (10); de 8 (6), de 12 (16) y de 14 (4).

En comparación con Espronceda, Zorrilla aumenta la escala en los metros mayores, ampliándola con el alejandrino. Igual que él, omite el tridecasílabo, bastante insólito en español. Pero, a diferencia de Espronceda, omite también el eneasílabo en las

${ }^{21}$ Dentro de esta larguísima serie de tetrasílabos hay que destacar dos octosílabos tipográficos (que hemos computado como 4 tetrasílabos, para no romper el esquema de la escala): «en el fondo de su pecho / con su luz iluminó./ Luz postrera / de esperanza», (etc.).

La unión o la prolongación en estructuras próximas se aprecia también al final de la escala: en los dodecasílabos incluye dos sextetos de 2 rimas alternas, el segundo de los cuales se prolonga en los 4 versos de un serventesio que rima con el segundo sexteto («quizá» // «ciudad» / «paz»), y rimará a su vez con el serventesio alejandrino siguiente («ya» / «va»). 
dos ramas de la escala. Igualmente suprime el pentasílabo en la rama descendente, y el decasílabo y endecasílabo en la ascendente. Es una escala amplia pero incompleta.

En cuanto a los tipos poemáticos, tenemos, respectivamente: octava de dos rimas alternas; tres serventesios, cuarteta, serie, doce octavillas agudas, ${ }^{22}$ serie (87 versos), octavilla aguda, serie, cuatro octavillas agudas, serie, sextilla de 2 rimas alternas, dos sextetos de 2 rimas alternas, y dos serventesios.

"La azucena silvestre" presenta, pues, polimetría y heteroestrofía.

La segunda escala la hallamos en el capítulo primero de "Un testigo de bronce". La rama descendente de la escala y la ascendente están separadas por un romance heroico de 48 versos. Dejando éste aparte, encontramos en la rama descendente las siguiente medidas: 14 sílabas, $12,11,10,9,8,7,6,5,4$, 3 , 2 y 1 . Por tanto, menos el tridecasílabo, todos los demás metros entre las 14 y la 1 sílaba están representados. En la rama ascendente volvemos a encontrar las mismas medidas en el orden inverso.

Podemos afirmar que ésta es la escala más breve de Zorrilla, con 227 versos (93 en la rama descendente, y 134 en la ascendente). ${ }^{23}$ ("La azucena silvestre" tenía 328 versos, y la "Leyenda de Al-Hamar" tendrá nada menos que 513). Al mismo tiempo, "Un testigo de bronce” es la más regular, pues repite con exactitud los mismos metros en ambas ramas de la escala.

En cuanto a los tipos métricos que configuran esta escala, encontramos, para la rama descendente: cinco serventesios (uno para cada conjunto de versos, entre las 14 y las 9 sílabas), tres cuartetas (para los conjuntos de 8,7 y 6 sílabas), y cuatro

${ }^{22}$ En los hexasílabos de la rama descendente de la escala encontramos una curiosidad métrica: dos octavillas agudas tipografiadas seguidas, sin blanco, en forma de serie, y prolongadas por otros cuatro versos a modo de coda, que enlazan mediante el verso agudo («quizá») tanto con la estrofa anterior («ya») como con la siguiente, tetrasílaba («va»).

23 El reparto de los distintos conjuntos de versos es éste: $4+4+4+4+4+4+4$ $+4+9+11+29+12=93$ versos; $16+31+10+14+11+10+8+7+5+6+5+5+6134$ versos. (Total: $93+134=227$ versos). 
series (para los versos más breves de 5, 4, 3, 2 y 1 sílabas), -gramaticales estas últimas, no métricas-). En la rama ascendente volvemos a encontrar: series para los metros más breves, que ahora afectan a los de 1 y 2 sílabas, 3, 4 y 5, extendiéndose la serie a las 6 y las 7 sílabas; octavilla aguda en los octosílabos; séptima en los eneasílabos; quinteto en los decasílabos dactílicos; sexteto agudo en los endecasílabos; quinteto en los dodecasílabos compuestos; nuevamente quinteto en los cinco alejandrinos primeros; y finalmente sexteto agudo en los alejandrinos finales.

Por último, la “Leyenda de Al-Hamar” contiene una escala métrica descendente-ascendente. Cada parte aparece con un título próximo pero independiente: "La carrera, I" y "La carrera, II”. Ambas están separadas por el "Libro de las Nieves” (16 octavas reales). Presenta esta escala métrica la sobrenatural galopada que realiza el caballo del príncipe de Granada Al-Hamar, y su aquietamiento posterior. En el ramal descendente de la escala encontramos metros de: 14 sílabas (16); 12 (dodecasílabos dactílicos compuestos: el verso de “arte mayor”, 16); 11 (16); 10 (decasílabos dactílicos, 32); 9 (16); 8 (16); 7 (64); 6 (72); 5 (59); 4 (102); 3 (23); 2 sílabas gramaticales -3 métricas- (7) y 1 sílaba gramatical -2 métricas- (7). ${ }^{24}$ Todos los metros, pues, entre las 14 y la 1 sílaba menos el tridecasílabo.

Los mismos metros, menos el hexasílabo -por tanto, entre 1 sílaba y 14, exceptuando de nuevo las 13-volvemos a encontrar en el ramal ascendente, "La carrera, IV". Respectivamente son: monosílabos gramaticales -métricamente bisílabos- (4); bisílabos (2: 1 gramatical y métrico, más 1 trisílabo métrico); tetrasílabos (10); pentasílabos (11 ); heptasílabos (8); octosílabos (4); eneasílabos dactílicos (4); decasílabos dactílicos simples (4);

${ }^{24}$ He aquí el número de versos contenido en los distintos conjuntos: 14 sílabas (8+8); de 12 (dodecasílabos dactílicos compuestos: el verso de "arte mayor", 8+8); de 11 (8+8); de 10 (decasílabos dactílicos, 8+8+8+8); de 9 (8+8); de 8 (8+8); de 7 (64 versos: 8 octavillas); de 6 (72 versos: 7 octavillas y 2 conjuntos de 8 versos unidos por la rima); de $5(16+8+35)$; de $4(25+17+25+35)$; de $3(9+14)$; de 2 sílabas gramaticales (3 métricas) (7) y de 1 sílaba gramatical (2 métricas) (7). Total: 454 versos. 
endecasílabos (6); dodecasílabos dactílicos compuestos (3) y alejandrinos trocaicos (3). ${ }^{25}$

En cuanto a los tipos poemáticos incluidos en "La carrera, I" -la rama descendente-, encontramos, de modo correlativo: octava de 2 rimas, tres octavas de Víctor Hugo; ${ }^{26}$ dos octavas agudas (una simétrica y otra asimétrica); octava de Víctor Hugo; cinco octavas agudas; diecisiete octavillas agudas; serie de 8+8 versos unidos por la rima; octavilla aguda; y ocho series.

La rama ascendente, "La carrera, II”, presenta estos tipos poemáticos: serie; dos series de 10 y 11 versos enlazadas por la rima; octavilla aguda con coda (8+3); octavilla aguda; cuarteta; dos serventesios; sexteto agudo; y sexteto agudo dividido entre dos metros: el de 12 y el de 14, a manera de doble terceto:

(12) Ya cambia: ya el trote medido levanta, y, el cuello engallado, segura la planta, altivo en la sombra mirándose va.

(14)Ya lenta y suavemente su dueño le refrena: se acorta: ya en el paso su marcha va serena, recógele: obedece: paró. ¡Loado Alah!

En resumen, Zorrilla -al igual que Espronceda-, plantea estas escalas con metros entre el monosílabo gramatical y el alejandrino, omitiendo el tridecasílabo, del que seguramente ambos poetas no tenían conciencia. A diferencia de Esponceda y de Hugo, Zorrilla no gusta de los "rombos", y en cambio configura sus escalas en la forma más rara de dos triángulos unidos por el vértice, por tanto como escala descendente-ascendente.

Tratamiento aparte merece la escala triple contenida en el poema "Recuerdo del tiempo viejo" (1889). Concretamente, en las partes II ("Salmodia”), III y IV (sin título propio). Decimos que merece tratamiento aparte, primero por encontrarse descolgada

\footnotetext{
${ }^{25}$ El cómputo de versos en los distintos metros de "La carrera, II", presenta estas cifras: $4+2+10+11+8+4+4+4+6+3+3$. Total: 59 versos. Así pues, sumados los dos ramales de la "Leyenda de Al-Hamar", tenemos: 454+59=513 versos.

${ }^{26}$ Esquema AÉAÉBBBÉ, tal como aparecía en “Les Djinns”.
} 
cronológicamente de las anteriores (es 37 años posterior a la última). Segundo, porque viene cinco años después de un terrible ataque que el propio Zorrilla propina a la escala métrica en 1884 -como veremos en seguida-. Y tercero, porque aquí Zorrilla, siempre tan creativo y original, trata a la escala métrica no como si fuera un extenso poema -como hemos venido viendo hasta ahora-, sino como si fuera una estrofa o unidad métrica que puede repetirse para insertarla en una unidad superior o poema. Nadie había hecho esto nunca con la difícil escala.

"Recuerdo del tiempo viejo" aparece inserto en el hermoso discurso que pronunció Zorrilla con motivo de su solemne coronación en Granada (22 de junio de 1889). Agobiado por la edad, las enfermedades, el ánimo depresivo y la sensación de que su estro se encuentra en decadencia, traza aquí un panorama sintético de lo que ha sido su vida.

En la parte II, "Salmodia”, encontramos versos de 12, 6 y 3 sílabas, ${ }^{27}$ rematados por una palabra bisílaba aguda: "fugaz". La parte III, a manera de "antiestrofa” de la "estrofa” anterior, presenta los mismos metros (12, 6 y 3 sílabas), con numerosos paralelismos y repeticiones de la parte II. Sobre todo los hexasílabos y trisílabos son idénticos a los de la parte II, con ¡o que el poeta produce un efecto de larguísimo estribillo. Y, por último, la parte IV actúa como “épodo” o remate de los dos conjuntos anteriores. Comienza igualmente con versos de 12 sílabas, pero luego pasa a los de 8 sílabas, después a los de 4, y finalmente termina con tres monosílabos (bisílabos métricos): «¡Se / fue/ ya!».

Zorrilla cierra la escala métrica en la literatura española. (Sólo Rubén Darío, unos pocos años antes, la cultiva en Nicaragua). Y, curiosamente, también de Zorrilla va a venir la crítica más acerba que recibirá este poema mixto. Podríamos decir, pues, que Zorrilla escribe, junto con el mayor número de escalas métricas, su acta de defunción.

${ }^{27}$ Igual que en "La azucena silvestre”, donde entre la serie de tetrasílabos hallábamos algún octosílabo, aquí Zorrilla intercala en las series de trisílabos algunos hexasílabos, que no rompen el ritmo pero sí la imagen visual de la escala. 


\section{6. Decadencia y desaparición de la escala métrica}

En la reimpresión de la leyenda "Un testigo de bronce", en 1884, el propio Zorrilla escribe estas palabras, muy reveladoras de que en ese momento ya la escala métrica había pasado de moda y le molestaba haberla cultivado:

Precede a esta leyenda una especie de sinfonía, que no parece otra cosa la escala métrica en que describo la pesadilla del primer personaje que en mi relato presento.

Eran, por los años en que esto se publicó [1845], una manía los alardes de versificación, y desde que Víctor Hugo escribió sus Djinns no pudimos creernos poetas sin hacer un rombo o escala métrica. Espronceda y la Avellaneda tienen el suyo, y yo he perdido mi tiempo en confeccionar tres o cuatro, uno de los cuales es esta introducción del TESTIGO DE BRONCE. [...]

[...] Basta para prueba de los desvaríos de escuela y de los extravíos del gusto; por más que sea también prueba del poder del estudio y de la facultad de versificar. [...] [H] oy sólo me toca lamentar mi audacia juvenil y reconocer mis desatinos; entre los cuales no ha sido el menor la manía de amplificar los pensamientos y de miniar y afiligranar la versificación.

Para terminar, señalemos como curiosidad que, además de existir escalas métricas en la literatura francesa y en la española, existe también en la italiana. Zorrilla, en la misma reimpresión de "Un testigo de bronce", ${ }^{28}$ cita una italiana, «mejor que todas las castellanas, del autor anónimo de "In solitudine": su argumento es también el sueño, más amplio que el del mío, que no es más que una pesadilla». Señala igualmente que la pieza italiana no le pudo servir de inspiración para las suyas «porque es moderna». Y añade que la lengua italiana sería la única «a la cual podría perdonarse tan extravagante capricho» como una escala métrica. Primero -sigue diciendo Zorrilla-, porque sus plurales terminan en vocal (y no en eses silbantes y ásperas como la castellana), y segundo porque es rica en monosílabos, «dos ventajas inmensas ${ }^{28}$ Páginas 2216-2217 de Obras Completas, I. 
que Italia tiene sobre nosotros para su armonía y la melodía de la metrificación».

\section{7. Una escala rezagada: Rubén Darío (c. 1884)}

Podríamos, pues, suponer que hacia 1884 el uso de escalas métricas había caído en desgracia. Y sin embargo, por esas mismas fechas (entre 1880 y 1886), el adolescente Rubén Darío (1867-1916) compone una escala ascendente-descendente (en forma de rombo, como las de Victor Hugo y Espronceda): "Tú y yo”. Forma parte de las poesías dispersas anteriores al viaje a Chile del poeta (1886).

La escala de Rubén es bastante extensa: consta de 201 versos. Incluye metros entre las 2 y las 14 sílabas, descendiendo nuevamente. Son éstos: $2,3,4,5,6,7,8,9,10,11,12,14,12,11,10$, $9,8,7,6,5,4,3$ у $2 .{ }^{29}$

Al igual que Espronceda y Zorrilla, Rubén Darío no incluye el tridecasílabo -metro que cultivaría más tarde, sobre todo en su variedad de tridecasílabo ternario, inserto entre alejandrinos- ${ }^{30}$ Como ellos también y como Avellaneda, prefiere las variedades dactílicas de los eneasílabos, decasílabos y dodecasílabos (compuestos, en este caso).

La dificultad de la escala métrica para el joven poeta se evidencia en un rasgo no visto en los autores anteriores: Con una cierta frecuencia, Darío se sale de la obligada isometría dentro de cada uno de los conjuntos de metros, para introducir pies quebrados, rompiendo la igualdad de cada conjunto. ${ }^{31}$ La polimetría típica de la escala recibe, en Darío, un suplemento de heterometría.

En cuanto a los tipos poemáticos englobados en esta escala, son los siguientes: octavilla romántica (7), series (2), decimillas

${ }^{29}$ La distribución de los 201 versos entre estos metros es, respectivamente: $8+8+12+$ $8+10+10+10+8+9+4+4+8+4+12+4+4+5+9+12+9+8+8+11+8+8$.

${ }^{30}$ Para un estudio exhaustivo del metro de 13 sílabas, véase Julio Saavedra Molina: “El Tredecasílabo” (1946: 24-62). Sobre los tridecasílabos y sus tipos, I. Paraíso (2002: 132-133 y 135-139).

${ }^{31}$ Así en rama ascendente, en los grupos de 3 sílabas (donde introduce un monosílabo) y 12 (con un hexasílabo); y en la rama descendente, en los grupos de 12 (nuevamente con hexasílabo), y 10 (con un tetrasílabo). 
románticas (2), romance (2), cuarteto asonante ØAØA (3), cuartetos pareados (4), serventesios (3), cuarteto (1), quintetos (2), novenilla romántica (1), y undécima romántica (1). En el uso de la heteroestrofía, pues, Rubén continúa la práctica de Espronceda y Zorrilla.

Por todos estos rasgos, “Tú y yo” forma parte del aprendizaje poético del jovencísimo nicaragüense, que en este momento se alimenta de fuentes románticas. Podemos también sospechar que el inquieto y fértil joven poeta posiblemente se planteó la escala como reto personal. Con toda su carga romántica, no deja de ser ilustrativo encontrarla en quien poco después (1888) pasaría a encabezar el Modernismo con su libro Azul.

La escala métrica en él ya ha perdido su temática característica de horror, sobrenaturalidad o pesadilla, para quedar reducida a un ejercicio métrico de temática amorosa y ligera.

\section{Huida del ritmo regular: la experimentación rítmica}

El ataque de Zorrilla en 1884 a la escala métrica muestra su finísima sensibilidad literaria. Aunque reconoce en quien la cultiva la habilidad versificatoria, la califica de "alarde", y critica en ella la amplificación de pensamientos y la filigrana métrica. Sobre todo, la considera como forma poemática de moda en torno a 1840; y cuarenta y cuatro años después, pasada ya su efervescencia, deplora haberla usado.

(Ello no le impide volver a utilizarla en los momentos finales pero más gloriosos de su vida, en el solemne acto de su coronación como Poeta: en "Recuerdo del tiempo viejo". La emplea tal vez como nostálgico emblema de su pasada capacidad poética y facilidad métrica. Pero aun en esas patéticas circunstancias de exaltación externa y conciencia interna de declive, la genialidad de Zorrilla le conduce a emplear la escala de manera estrófica, en una última y hermosa innovación).

Pero hacia 1884, cuando Zorrilla ataca la escala métrica y Rubén Darío está escribiendo la suya, estaban variando muchas 
cosas en la poesía occidental y en la española, y todas iban en la dirección de flexibilizar el ritmo, hacerlo cambiante, imprevisible incluso. La escala, con su sistemática polimetría, tenía que resultar anacrónica.

Recordemos que Walt Whitman publica Leaves of Grass entre 1855 y 1892. Que el verslibrisme francés cuaja en textos entre 1886 y 1888. Que en 1885 aparece En las orillas del Sar, de Rosalía de Castro, donde -como hemos analizado en otro lugar $-{ }^{32}$ se condensan las rupturas rítmicas románticas (mezcla de metros pares e impares en la estrofa; fractura de la estrofa) e incluso aparece algún metro nuevo (18 sílabas) y, sobre todo, alguna forma versolibrista. Recuérdese también que lo que hemos llamado "heterometría cambiante”, surgida en el siglo XVIII, intensifica su presencia en Bécquer (1836-1870; Rimas, escrito hacia 1867) y en Rosalía. Y, por último, tengamos presente que en 1892, ocho años después de las duras palabras de Zorrilla y sólo tres después de su “Recuerdo del tiempo viejo”, aparecerá el verso de cláusulas libres en José Asunción Silva. ${ }^{33}$

No seríamos, sin embargo, justos con la escala métrica de los años 1828-1889 si no viéramos precisamente en ella, en la fastuosidad de su polimetría, una búsqueda del contraste rítmico sucesivo, en el inquieto ir pasando de unos metros a otros. No en balde surge en Victor Hugo en un momento personal de intensa indagación rítmica.

Incluso en la versión heteroestrófica de la escala, que los poetas hispánicos realizan siempre (salvo Avellaneda), podemos ver un debilitamiento de la estrofa, rasgo que irá acentuándose en las décadas siguientes (Rosalía, p. ej.) hasta desembocar en las series versolibristas.

${ }^{32}$ I. Paraíso (1986, 11: 285-293).

${ }^{33}$ Sobre la historia y la tipología del verso libre en lengua española, cfr.: María Victoria Utrera Torremocha (2001) e Isabel Paraíso (1985). Para un enmarque del verso libre en la versificación irregular occidental, véase también Esteban Torre (1999: 15-26). 
Y, por último, señalemos que esa "poésie pour les yeux» que, en palabras de un contemporáneo ${ }^{34}$ de Victor Hugo es la escala (con su tipografía creciente y decreciente, que pone a prueba la habilidad del linotipista), constituye un importantísímo precedente de Mallarmé ( «Jamais un coup de dé n’abolira le hasard») y de toda la poesía visual de las Vanguardias.

Dentro de la amplia serie de poemas mixtos que surcan toda la Literatura, la escala métrica constituye, sin duda, un caso de brillantez extrema.

\section{Bibliografía}

AQUIEN, Michèle: La versification. Paris, P.U.F., 2a ed. corr., 1992 (1 ${ }^{\text {a }}$, 1990).

BAUSI, Francesco, e MARTELLI, Mauro: La metrica italiana. Teoria e storia. Firenze, Le Lettere, 1993.

BELLO, Andrés: Obra literaria. Caracas, Biblioteca Ayacucho, 1979.

BELTRAMI, Pietro G.: La metrica italiana. Bolgna, II Mulino, 1991 (2ª ed. 1994).

DARÍO, Rubén: Poesías completas. Madrid, Aguilar, 1968.

DOMÍNGUEZ CAPARRÓS, José: Diccionario de métrica española. Madrid, Alianza, 1999.

ESPRONCEDA, José de: Poesías y El estudiante de Salamanca. Prólogo y notas de José Moreno Villa. Madrid, Espasa-Calpe, Clásicos Castellanos, 1962.

-El estudiante de Salamanca y El diablo mundo. Ed. de Robert Marrast. Madrid, Castalia, Clásicos Castalia, 1989.

GÓMEZ DE AVELLANEDA, Gertrudis: Poesías y Epistolario de amor y de amistad. Madrid, Castalia-Instituto de la Mujer, 1989.

GRAMMONT, Maurice: Le vers français. Ses moyens d'expressions, son harmonie. Paris, Delagrave, 6e éd. 1967.

HUGO, Victor: Oeuvres poétiques. Vol. I: Avant l'exil, 1802-1851. Préface par Gaetan Picon; éd. établie et annotée par Pierre Albouy. Paris, Gallimard, nrf, Bibliothèque de La Pléiade, 1964.

NAVARRO TOMÁS, Tomás: Métrica española. Barcelona, Labor, 1991.

PARAÍSO, Isabel: El verso libre hispánico. Orígenes y corrientes. Madrid, Gredos, 1985.

${ }^{34}$ Un crítico en Le Globe, enero de 1929. Apud Pierre Albouy, cit.: 1229. 
— “La audacia métrica de Rosalía de Castro (En las orillas del Sar)”. Actas do Congreso internacional de estudios sobre Rosalía de Castro e o seu tempo. Universidade de Santiago de Compostela, 1986, t. II: 285-293). - La métrica española en su contexto románico. Madrid, Arco / Libros, 2000.

SAAVEDRA MOLINA Julio: Tres grandes metros: el Eneasílabo, el Tredecasílabo y el Endecasílabo. Tirada aparte de Anales de la Universidad de Chile, 1946.

TORRE, Esteban: El ritmo del verso. Murcia, Universidad de Murcia, 1999.

UTRERA TORREMOCHA, María Victoria: Historia y teoría del verso libre. Sevilla, Padilla Libros, 2001.

ZORRILLA, José: Obras Completas, 2 vols. Ordenación, prólogo y notas de Narciso Alonso Cortés. Valladolid, Librería Santaré, 1943. 